\title{
Research on the Historical and Regional Cultural Elements in Cityscapes of Yili, Xinjiang
}

\author{
Jiaying Liu ${ }^{1}$, Menghu Wang ${ }^{2}$, and Weiwei Lei $^{3}$ \\ 1(Department of Chinese Language and Literature of Northwest Minzu University, Lanzhou, Gansu, China, P.R. \\ Lanzhou City University, Lanzhou, Gansu, China, P.R.) \\ 2(Lanzhou City University, Lanzhou, Gansu, China, P.R.) \\ 3(Lanzhou City University, Lanzhou, Gansu, China, P.R.)
}

\begin{abstract}
Xinjiang, since it became affiliated with the central plain dynasty once again in the middle of the Qing Dynasty, has been committed to city building and construction in batches, aiming to reinforce military defense and develop economy through reclaiming outlying wasteland. Yili is a area of renown in history that remains geographically essential to the military defense of China's northwestern border. Starting from its regional culture, this paper analyzes the cultural elements incorporated in its historical cityscape planning, which principally encompass geographical landmarks, ethnicities, religions among other cultural landscapes, and elucidates the necessity of integrating regional culture and landscape design, in an attempt to furnish approaches to exploring and carrying forward traditional regional culture, preserving cultural landscapes unique to this area, and displaying the peculiar enchantment.
\end{abstract}

\section{Overview}

Recent years have seen substantial progress taking place in China's city construction. Under the guidance of modernized design methods, great importance is attached by local government to landscape design, so considerably abundant manpower and material resources are dedicated to its preliminary development and post maintenance. Nevertheless, characteristics of localization tend to be in successive decline in the process of drawing experience from foreign city design styles and techniques of excellence, ending up with stereotype and homogeneity. Stereotyped cityscape design is bound to obscure the line of regional culture between different places and leave regional humanistic characteristics and historical appeal fading, losing cultural and spiritual significance in the long term. Currently China's cityscape design is liable to be in standardization and in shortage of peculiarities, homogenizing city modes that vary prior to renovation. The rapid development of contemporary economy and technology is accompanied by a groundswell of advocacy for indigenous and regional culture. To enhance the balance between regional culture and landscape design entails effective regional technologies and greater efforts into the development and utilization of traditional culture so as to present block landscapes reflecting this city's peculiarities.

To figure out how to maintain the enduring vitality of cityscape design, the origin and history of city space can help. "A relationship network composed of space elements, which critically influence a city's spatial form, manifests the context externally through spatial form, normally reflects certain connection established between space, human, nature and society during a fixed period of time, and condenses the essence of city spatial form and culture."1 While globalization and China's urbanization accelerate, city spatial form is increasingly "fragmentized" under the protection concentrating on its form but neglecting context inheritance. The Silk Road has been reborn since "the Belt and Road Initiative" was proclaimed and an ambitious program was launched to construct the Silk Road Economic Belt. Yili is a famous historical and cultural area in China along the Silk Road with abundant historical and humanistic heritage thanks to its special location and time-honored history and culture. The exploration and research of this area's spatial context prove an imperative issue for its protection and development in optimized manner.

\section{Site Selection and Building of Cities in Yili in the Qing Dynasty}

Among studies on city's history and historical geography is research on site selection of China's ancient cities, an essential field that takes into consideration the factors of "natural environment (including macro environment and micro topography), traffic routes, and economic conditions apart from less frequent political climate and other historical and humanistic conditions (e.g. relocating the capital)". Despite the fact that Yili possesses a superior geographical location in Xinjiang and a favorable environment for agricultural cultivation, which suffices to illustrate it is highly probable for cities to arise, selection 
of specific site is subject to contemporary situation and people in charge. In consequence, to explore site selection of Yili's nine cities both at the macro and micro level without neglecting the factor of "human" can help draw a more comprehensive conclusion.

With regard to studies on the cityscape culture of Yili, $\mathrm{Wu}$ Yiqun, based on analysis of the rank of city size, spatial distribution, and functions, claimed that between the nine cities "explicitly exists an essential relationship featuring geographical proximity, complementary functions and size in sequence, which indicates that Yili's city system has already been established and begun to develop as early as Emperor Qianlong's reign in the Qing Dynasty," 2 and maintained that "such system, with political and military deployment as the principal purpose and reclaiming wasteland and grazing by stationed troops and peasants as economic security, is characteristic of comprehensive layout, functional complementarity, convenient traffic and national segregation." Wang Yan argued that Yili's nine cities were an organic whole composed of city settlements and quasi city settlements. ${ }^{3}$

Each area possesses its peculiar regional culture of incomparability which constantly accumulates and form regional industrial culture ranging from distinctive natural scenery to customs and to historical conventions. The development of regional cultural elements not only helps display local cultural connotations and artistic appeal but serves as a city symbol during promotion helpful to demonstrate environment and functions unique to this city. The following topographic map of Yili in the Qing Dynasty shows that this imperial court determined at that time to reclaim wasteland on a large scale and build forts in this region to unify Xinjiang and guard northwestern China by capitalizing on the important strategic position of the Yili Valley. It was at this period of time that Yili's nine cities were constructed successively, which served as a cornerstone for the subsequent over centennial military rule. It follows that the nine cities at least appeared essential in Xinjiang's political, military and city history during the Qing Dynasty.

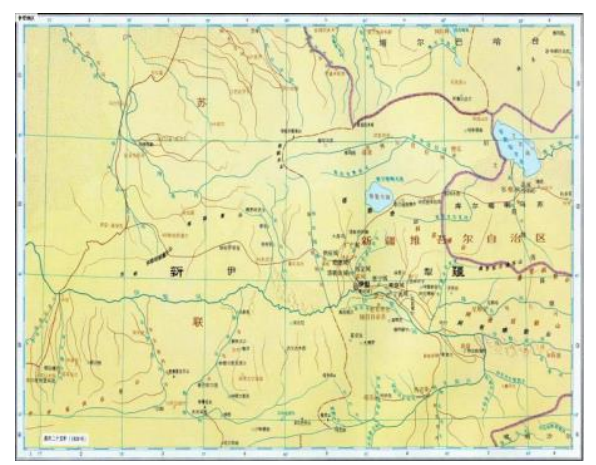

Fig. 1 Historical Atlas of China, Yili Region in the Qing Dynasty, Tan Qixiang

\section{Yili's Architectural and Garden Cultural Landscapes in the Qing Dynasty}

Cities which existed in Yili region prior to the Qing Dynasty were unfortunately obliterated from history mostly due to geographical changes, turmoil caused by wars, and migration of ethnic groups among other natural and human factors, which explains why literature in the Qing Dynasty reads that "not a single city has ever existed in Yili before". The nine cities were initially constructed and expanded in the reigns of Emperor Qianlong and Jiaqing (1736-1820), which profoundly and lastingly influence the development of this region's cities and the formation of city system. It is safe to say that Yili's city system originated from the nine cities. After the Qing Qianlong Emperor pacified the Western Regions, nine cities inhabited by the Manchu, Hui, Han and Uyghur nationalities were constructed in Yili, while the General of Yili (aka Kuldya Military Governor in western sources) was appointed to govern the entire region. Afterwards Yili played a central role among cities located in the Western Regions prior to the establishment of Xinjiang Province in the reign of Emperor Guangxu. In accordance with the topographic factors of the Yili Valley and the will of those officials led by the General of Yili, the foremost goal is to strengthen military defense and cultivate through reclaiming wasteland by garrison troops and peasants. An overview of all the cities in Xinjiang, which are adjoined or separated by difference in nationality, shows that mostly the city system is binary, whereas Yili comprises nine cities, which is unique in all over Xinjiang and even the entire Central Asia.

The nine cities are Huiyuan, Huining, Ningyuan, Suiding, Gonggu, Zhande, Guangren, Xichun and Taerqi city. Nearly over twenty years from 1761 to 1780 was spent on the construction of Yili's cities. The motivation shifted from resettling indigenous Uyghurs, who migrated from Southern Xinjiang in attempt to reclaim wasteland, to expanding the encampments required by Manchu for garrison, and to resettling soldiers in Green Battalion, a regular army gaining its name for holding green army flag, and their households who came after them, causing people to proliferate. The Qing Dynasty determined at that time to reclaim wasteland on a large scale and build forts in this region to unify Xinjiang and guard northwestern China by capitalizing on the important strategic position of the Yili Valley. It was at this period of time that Yili's nine cities were constructed successively, which served as a cornerstone for the subsequent over centennial military rule. It follows that the nine cities at least appeared essential in Xinjiang's political, military and city history during the Qing Dynasty.

Among the cultural landscapes of Yili's previous architecture in ancient times are city walls, gate towers, pavilions, temples, gardens (private or public), academies and guild halls. Some have long since been untraceable, while those surviving today serve as a bellwether for building cultural heritage landscapes and shaping cities' cultural characteristics in Xinjiang. For instance, Huiyuan city, where the General of Yili was garrisoned, at that time covered an area overtaking that of most other cities in Xinjiang. To date, the "General Office of Yili" has still been preserved among other historical and cultural monuments. Conversely, Wanghe Tower, a culturally famous building constructed on the northern bank of Yili 
River in the middle years of Emperor Qianlong's reign, has vanished due to collapse caused by ever-shifting banks, despite its fame gained from the plaque on which the chief executive of Yili once inscribed characters personally, and the numerous poems of excellence composed during gatherings by Lin Zexu, Deng Tingzhen and other cultural figures who were banished to the Western Regions. Researchers dedicated themselves to cityscapes are expected to ponder whether it is possible to add another cultural symbol to Yili by restoring this tower in accordance with a trail of clues captured from historical documents. Only by clarifying the relationship between regional culture and landscape design and forming new aesthetic culture, can more abundant fruits be yielded of relevance to unique and diversified cities. In doing so, folk culture will endure and meanwhile a balance of coexistence can be maintained between such culture and cityscapes.

\subsection{Religious and Folklore Cultural Landscapes}

Xinjiang, called the junction of four major cultures in ancient times, is home to a blend of ethnic groups and a culturally diversified area whose custom and religious buildings possess characteristics of local culture. Altars, temples and shrines in Huiyuan city were distributed at the four gates of forts and in the building of chief executive's office in those days. The Qing Dynasty merged the beliefs held by the Manchu, Mongol, Hui, Uyghur and Han nationalities at the approximate time of initiating city construction, clues of which could be found from the settings of altars and temples. A saying goes that "the Ming Dynasty concentrated on constructing the Great Wall while the Qing Dynasty was dedicated to the construction of temples." Beliefs and sacrifice rituals abounded and varied in the Western Regions during the Qing Dynasty, where existed not only religious beliefs traditionally unique to this place, such as Huang Temples and Fan Temples embraced by both the Mongol nationality and the Tibetan nationality, but deities' shrines and temples for Buddhist, Confucian and Taoist, three common beliefs in inland that all appeared in the Western Regions. Additionally quite a few historical figures who were worshiped by the public were honored in ancestral halls and temples specifically built for them. Each place of Yili once served as the front of battlefield, where the defense of forts not only determined the outcome of wars and China's territory integrity, but remained extremely vital to the lives of common people and soldiers. This place was more vital strategically in comparison with cities situated in the Central Plains. Consequently, civilians and soldiers expressed their obsession with and longing for their homes and peace by means of worshiping cities' patron saints, in particular God of Martial Arts and God of War.

These temples among other similar buildings have witnessed the vicissitudes of Yili to date. For some buildings, changes occurring over time, and the expansion strength, type and flexibility of construction land in cities

Many literati from Yili boarded the "Jianyuan Tower" and "Wanghe Tower", they wrote poems with this title. The scholar Qi Qingshun speculated: "It can be seen from the poems that leave it unlikely to reproduce exact replicas. Nevertheless, efforts to tease out the placement of religious cultural landscapes in Yili will remarkably contribute to presenting original cultural landscapes and creating city symbols unique to this place.

Table 1. Distribution of altars and temples inside and outside the Huiyuan city during the reign of Emperor Qianlong in the Qing Dynasty

\begin{tabular}{|l|l|l|l|l|l|}
\hline $\begin{array}{l}\text { Altar } \\
\text { temple }\end{array}$ & $\begin{array}{l}\text { Establishin } \\
\text { g time }\end{array}$ & Location & $\begin{array}{l}\text { Altar } \\
\text { temple }\end{array}$ & $\begin{array}{l}\text { Establishin } \\
\text { g time }\end{array}$ & Location \\
\hline $\begin{array}{l}\text { Longevity } \\
\text { Palace }\end{array}$ & 1766 A.D & $\begin{array}{l}\text { Lai 'an } \\
\text { Gate } \\
\text { inside } \\
\text { (North } \\
\text { Gate) }\end{array}$ & $\begin{array}{l}\text { Emperor } \\
\text { Guan } \\
\text { Temple }\end{array}$ & $\begin{array}{l}\text { Built by the } \\
\text { beginning } \\
\text { of 1763. } \\
\text { Removed in } \\
1792\end{array}$ & $\begin{array}{l}\text { Set up Lai 'an } \\
\text { gate first. } \\
\text { Then } \\
\text { removed to } \\
\text { Yue Ze Men } \\
\text { Street (West } \\
\text { gate) }\end{array}$ \\
\hline $\begin{array}{l}\text { Bala } \\
\text { Temple }\end{array}$ & 1758 A.D. & $\begin{array}{l}\text { Drum } \\
\text { tower east }\end{array}$ & $\begin{array}{l}\text { Chenghu } \\
\text { ang } \\
\text { Temple }\end{array}$ & 1755 A.D. & $\begin{array}{l}\text { North Gate } \\
\text { inside }\end{array}$ \\
\hline $\begin{array}{l}\text { Vesta } \\
\text { Temple }\end{array}$ & 1792 A.D. & $\begin{array}{l}\text { Lai 'an } \\
\text { Gate } \\
\text { inside }\end{array}$ & $\begin{array}{l}\text { Wencha } \\
\text { ng } \\
\text { Palace }\end{array}$ & 1802 A.D. & $\begin{array}{l}\text { Jingren } \\
\text { gate(East } \\
\text { Gate) }\end{array}$ \\
\hline $\begin{array}{l}\text { General } \\
\text { Liu Meng } \\
\text { Temple }\end{array}$ & 1767 A.D. & $\begin{array}{l}\text { Drum } \\
\text { tower west }\end{array}$ & $\begin{array}{l}\text { Ancestra } \\
1 \text { Temple } \\
\text { One }\end{array}$ & 1766 A.D. & $\begin{array}{l}\text { Lai'an Gate } \\
\text { inside (North } \\
\text { Gate) }\end{array}$ \\
\hline $\begin{array}{l}\text { Deepcool } \\
\text { Temple }\end{array}$ & 1775 A.D. & $\begin{array}{l}\text { Yueze } \\
\text { Gate } \\
\text { outside }\end{array}$ & $\begin{array}{l}\text { Sheji } \\
\text { Altar }\end{array}$ & Unknown & $\begin{array}{l}\text { Southeast } \\
\text { corner of the } \\
\text { city }\end{array}$ \\
\hline $\begin{array}{l}\text { Agricultur } \\
\text { e Altar }\end{array}$ & Unknown & $\begin{array}{l}\text { Sheji Altar } \\
\text { north }\end{array}$ & $\begin{array}{l}\text { Puhua } \\
\text { Temple }\end{array}$ & 1767 A.D. & East bank \\
\hline $\begin{array}{l}\text { Laojun } \\
\text { Temple }\end{array}$ & 1763 A.D. & $\begin{array}{l}\text { Vesta } \\
\text { Temple } \\
\text { east }\end{array}$ & $\begin{array}{l}\text { Goddess } \\
\text { Temple }\end{array}$ & 1773 A.D. & $\begin{array}{l}\text { Yili General } \\
\text { office inside } \\
\bullet\end{array}$ \\
\hline $\begin{array}{l}\text { Kragon } \\
\text { Temple }\end{array}$ & 1775 A.D. & $\begin{array}{l}\text { (Xuankai } \\
\text { Gate) } \\
\text { South Gate } \\
\text { outside }\end{array}$ & & & \\
\hline
\end{tabular}

\subsection{Yili's Abundant Garden Landscapes in History}

It is not only because of its natural property but more importantly its humanistic property that a common landscape is recognized as a cultural landscape. As Xinjiang's military system matured and its administrative system under the lead of the General of Yili was established, officers and soldiers descended from the Manchu and Mongol noble families played a vital role in accelerating the construction of government offices' courtyards and gardens for the sake of recreation and social engagements when they perennially guarded the outlying border. Garrisons built residences with gardens in this territory. Renowned gardens that Yili and Urumqi alone possessed at that time exceeded ten. Those gardens in the outlying Western Regions naturally appeared not as splendid, elegant, charming and unique as those located in the capital city or south China. Nevertheless, they are private lands belonging to important officials, affluent merchants, and men of letters in the border, who developed their expected lifestyle and fostered the Western Regions' literature in these spaces.

Pavilion: "Jianyuan Tower" (looking far ahead), the most important one which is also known as Wanghe Tower, ${ }^{1}$ is situated on the northern bank of the Yili River,

The Wanghe Tower is like the Jianyuan Tower mentioned above, was also a great local scenic spot at that time. However, Shu Qisao recorded in listening to Snow in Volume 4: "The 
only a few miles to the Longwang (king of dragon) Temple located outside the southern gate of Huiyuan city. It was constructed under the inspection of Yilitu, the then General of Yili in the fortieth year of Qianlong Emperor's reign (1775) and later "Jianyuan" was inscribed on the plaque as its name. Jianyuan Tower was once cherished as a scenic spot for appreciating scenery, gathering and chanting poems by the Manchu and Han high officials, dignitaries, affluent merchants, and men of letters inhabiting in Huiyuan city. In the twenty-third year of Daoguang Emperor's reign (1842), Lin Zexu still mentioned this tower in his notes when banished to Yili despite the fact that it had been destroyed by floods nine years before (1833).

Gardens in literati's residences: 1) Huanbi Xuan (windowed veranda surrounded by greenery), an official mansion in the western city where the noted scholar Hong Liangji temporarily settled after convicted and banished to Yili for a hundred days by Emperor Jiaqing, was so named because in this place "there are hundreds of tall willows that stretch elegantly into the sky." 2) "Wuliu Yuan" (garden with five willows), the residence inhabited by Yang Tingli of Liuzhou, Guangxi Province who formerly held the post of prefecture administrator of Taiwan, was well-known for its tranquility and elegance, which were implied by him in the name. 3) Xipu Houseboat, the residence of Zhuang Zhaokui who was also a banished man of letters, was eulogized by him with long poems in the whole process of reclaiming wasteland, digging ditches to draw water, constructing houseboat, and ornamenting with stones. The aforesaid gardens furnish us with more cultural and historical materials useful to reveal literati's entertainment in the Western Regions at that time and investigate how they created unique garden landscapes simply by drawing on local limited resources and adjusting to changing circumstances.

Gardens: most were constructed in the reigns of Emperor Qianlong, Jiaqing and Daoguang, mainly distributed in Huiyuan city and peripheral cities. Statistics suggest as many as 16 parts existed ${ }^{2}$.

1) In Huiyuan city: the official residences and gardens inhabited by successive General of Yili were well-known for their splendor and magnificence which exceeded that of the remaining eight cities. Zhang Guangyan, Wei Peijin, and Lin Zexu all personally visited and recorded this city. Wei Peijin, who was employed by Song Yun, a Mongolian serving as the then General of Yili, after banished to Yili in the fifth year of Jiaqing Emperor's reign, once mentioned gardens' layout in government offices such as "Ye Tang" (Village Hall) and "Yi Garden". The rest were mostly private gardens, including Shi Guanglu's Xing Garden, the villar owned by a family surnamed Zhao, and De Garden owned by the Xieling (a government post of military officer) of Dexing city. Among those that were recorded in poetry anthologies but had obscure owners are Cheng Garden (success), Lvqi Garden (green and beautiful) and Pu Garden (Plain and Simple).

Wanghe Tower, namely the Jianyuan Tower, is on the north bank of the river, surrounding by the green trees. Snowcapped peaks encircle it.Fragrant grass and trees grow up and down the pavilion, it is the best sightseeing place.General Yili.

pavilion,it is the best sightseeing place.General Yili.
${ }^{2}$ Yile Tudu built this tower, and inscribed it as "Jianyuan Tower", commonly known as

"Wanghe Tower".After Shu Qisao, Wanghe Tower became another name for Jianyuan Tower.

For a detailed introduction of Yili gardens, please refer to Wu Huafeng's article "Garden
2) On the north of Huiyuan city: Xu Garden; the garden owned by a family surnamed Huo; two private gardens owned by Xilashan, one of which was $1.5 \mathrm{~km}$ north of Huiyuan city and another was situated in Hongshanzui (red mountain edge) that was also called Green Cloud Village and Hongxin Shanfang (houses established on the mountain of red apricots). Thousands of peonies grew in these two gardens. There existed also Yiachang's Yu garden (delight) which was slightly inferior to those owned by Xilashan.

4) On the southwest of Tacheng (also transliterated from Mongolian as Qoqak): Qie Garden owned by Zhuergenge, a person serving in the Han armies who was once appointed to inspect salt business in south China. $\mathrm{Xu}$ Song wrote in his Record of the Western Region Waterways that in this garden there was a tower called Mianmian Mountain Tower. He also wrote a pair of couplets for this tower by imitating Tao Yuanming's poetry.

5) In Suiding city: the garden with a pond called "Baizi Pond", owned by Zhang Yunqian, who was an official in charge of affairs pertaining to wasteland reclamation, Liu Huaxing's garden, Yan Shanfang's garden, and Sui Garden in the office of Zongbin (a military officer), which this study mainly focuses on.

\section{Other Places:}

In Kuchen of south Xinjiang: "Huanbi Tang" (literally meaning hall surrounded by greenery), the residence temporarily inhabited by Lin Zexu when he was charged to inspect the measurement of land acreage. Behind the residence was a garden covering several miles, in which there was a huge pond with a waterside pavilion and several rooms.

In Fuhua: "Zuiliu Garden" (literally meaning drunk willows), which was amban's office named by Bichang. Lin Kui, the amban of Wushi, once composed two poems called Zuiliu Garden, each of which comprised eight lines with seven characters to each line. Lin Zexu, after visiting the amban's office, wrote in his diary that "Behind the office is a small garden where crouched willows abound, and it is named 'Zuiliu Garden' by Bi Chang when he once went an arrand here."3

The major gardens' distribution in Yili in the Qing Dynasty is as shown in the following picture:

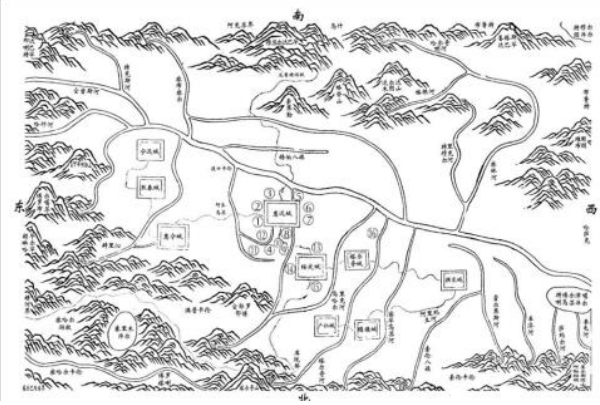

Fig. 2 This picture is from the passage "Yili's Garden

Architecture and Its Literary Performance in Yili in Qing Dynasty", which is included in the Literary history of Western Regions (Vol. 11). This article contains a list and a map to prove the gardens in Yili are. This paper refers to the data of landscape architecture in Yili region. ${ }^{3}$ Yi Si Diary, Volume 9 of The Complete Works of Lin Zexu, Fujian Strait Literature and Art Publishing House, 2002, p. 544. 
Architecture and Its Literary Expression in the Qing Dynasty" written by Wu Huafeng

Yili and Urumqi, two cities that historically served as the political center of Xinjiang in different times, possessed more gardens and pavilions than other cities. Gardens located in boundless borders form a unique field which feels like both an illusion and a reality and makes you transcend worldly time and space. Cavalier perspective of Chinese paintings also exists in gardens, which can help release all kinds of emotions and unfold stories with multiple aspects. Gardens seemed more like securely private "life stages" available to officials and men of letters in the Western Regions who lived in outlying lands, far away from the political center. "Gardens, which are binary in essence, reflect people's actual taste despite their artificial main parts, namely mountains and water." Nature in this context exists just as it did, while people need to select a place from it to settle themselves at ease, which is actually a typical psychological phenomenon - pursuit of nirvana, the socalled "Peach Flower Garden". Afterwards men of letters in official circles regarded living in gardens as a form of seclusion whereby they could cure, refresh, and entertain themselves, which was admitted as a paradigm of an ideal world. Nearly everything in gardens, including waterside pavilions, towers, ponds, windowed verandas, furnishings, articles in studies, tea, wine, flowers and trees, reflects the life of a man of letters. Meanwhile, gardens in some sense are the materialization of Chinese scholars' life philosophy.

The foremost issues in the design of city gardens, which remain extremely important to the whole cityscape planning, is to address the relationship between city development and ecological environment in real earnest, and deliver a sound ecological environment to lay a solid foundation for the steady and sustainable development of cities. ${ }^{4}$ Yili's public and private gardens historically adhered to the concept of "people-orientation" despite that this idea was immature at that time, which prompts people nowadays dedicated to garden landscape design to take historical and human factors into consideration. When undertaking their design tasks, designers are expected to take a holistic view without neglecting both people's needs and all kinds of environmental factors, to ensure that people feel at ease amidst gardens. To realize that purpose, a quantity of inspiration is available in

\footnotetext{
Tian Zhenzhen, Spatial Context Study of Typical Historic Cities along the Silk Road, Master thesis of Xi 'an University of Architecture and Technology, 2018.

2 Wu Yiqun, Comparative Study of Xinjiang Border Area Cities in Oing Dynasty: With Yili and Kashgar as the Center, Doctoral dissertation, Fudan University, 2007.

3 Wang Yan, Research on the History and Geography of The Nine Cities of Yili, Master thesis of Tianjin Normal University, 2019.
}

historical and cultural materials, texts and images.

\section{Conclusion}

In summary, in cities and regions along the ancient Silk Road survive a considerable number of cultural resources with marks of different times. The integration of cityscape design and regional culture helps enrich city connotations in a complementary way. Attention should be paid to both history and reality to carry forward regional culture in local places, so that folk culture will endure and meanwhile a balance of co-existence can be maintained between such culture and cityscapes. A review of Yili's development history demonstrates that it is a culturally diversified border region whose unique cultural landscapes have witnessed the vivid cultural history depicted by the fusion of diversity and prosper. Classification, selection, protection and application of these landscapes will present a vivid picture of the entire region's future.

\section{Acknowledgement}

This paper is one of the phased results of the Young Teachers Project No. : LZCU-QN2017-16.

\section{References:}

1. (Qing dynasty) Fu Heng et al., The Imperial map of the Western Regions ( photocopies of Wenhai Press, Taipei, 1970)

2. (Qing) Yuan Dahua, Wang Shannan et al., Notes by Zhu Yuqi, Xinjiang Atlas (Shanghai Ancient Books Publishing House, 2017.)

3. Wan Suchun.Analysis of urban spatial form. (Science Press,2004.)

4. Yu Sujian, Yuan Shuqi.Systematic Thinking on the Basic Problems of urban context Journal of Jilin Normal University (Natural Science edition),No.4. (2010)

5. Cheng Yinong, Reflections on Research Methods of Urban Site Selection in Ancient China, ( Chinese Historical Geography, 01, 2012)

\footnotetext{
${ }^{4}$ Gao Peigang, Key Points of Humanized Design of Landscape Architecture in Urban Landscape Planning, Urban Construction Theory Research (electronic Version), issue 17, 121+128. (2020)
} 